\title{
Investigation Impact of Salt, M:L, Soda Ash on Cotton, and Cotton Viscose Blended Fabrics Dyeing Using Direct Dyes
}

\author{
Md Abu Darda*, Md Tanvir Hossain, Nadim Mahmud, Abdur Rahman Talha and Md Abu Asad \\ Dhaka University of Engineering and Technology, Bangladesh
}

*Corresponding author: Md Abu Darda, Department of Textile Engineering, Dhaka University of Engineering and Technology, Gazipur-1707, Bangladesh.

Abstract

Direct Dyes are molecules can adhere with fabric molecules without any help from chemicals. It is anionic dyes with good substantivity for cellulosic fibers. This study attempts to investigate impact salt, M:L, Na2CO3 on knit fabrics (cotton and viscose cotton blended) dyeing by using direct dyes. Although a large number of research works have been accomplished in this field, a significant investigation still required. Research findings state that the absence of Salts and Soda Ash decrease the overall dye take-up as well as decrease of Material: Liquor increases the dye absorption or take-up of the knitted sample. Also, viscose cotton blended specimen shows less dye absorption and overall lower result comparing cotton.

Keywords: Direct dyes; Substantivity; Cotton; Viscose; Color fastness; Salt; Material; Liquor; Soda ash

\section{Introduction}

Cotton dying with direct dye is a very common and easy process. Direct dye is called easy on and easy off dye. Direct dyes have built-in substantivity for cellulosic fibers especially cotton. Their dyeing process usually in the attendance of an electrolyte like $\mathrm{NaCl}$ or $\mathrm{Na}_{2} \mathrm{SO}_{4}$. These dyes have been replaced to a magnificent extent by reactive dyes, which have better wet fastness and exceptional brightness in many hues [1]. To meeting severe wet fastness requirements and compete higher effectivity the development of direct dye of specialized after treating agents and crosslinking reactants [2].

A wide variety of different types of auxiliary chemicals are employed to dye fabric. Salt is one of the most important auxiliaries. In the case of using direct dye, the influence of added salt is the most vital factor in the dyeing of cellulosic fibers with direct dyes. In the dye house, there are two key point has considered: good exhaustion as well as good color uniformity. Both rely on the salt-controllability of the dyes, or how the progressive salt additions while dyeing influence the rate of exhaustion [3]. This is certainly the case for direct dyes. This indicates that dyeing at a low liquor ratio decreases the amount of waste dye in the effluent. It also consumes less water and steam and allows a given salt concentration with less added salt. There has been a strong trend towards dyeing at low liquor ratio as is practicable [4]

Due to COVID-19 pandemic, the demand for antimicrobial treated fabrics is reached at the peak and direct dye has a prospect to catch these antimicrobial treated fabrics. Direct dyes have properties to antimicrobial activity against Gram-positive and Gram-negative bacteria by taking after-treatment with copper and zinc sulfates [5]. Most prominent and mostly practiced cotton fiber has the potentiality of getting antimicrobial finish. By undertaking 
after-treatment different value-added properties like an antimicrobial finish, good wash fastness, lightfastness is attained [6].

Hence, the Importance and industrial uses of direct dye will be a rise in the post-pandemic economy. At the meantime, will increase awareness of sustainability issue thus need to learn optimum level of chemicals as well as impact of different parameter regarding dyeing [7]. Although several researchers have been accompanied in this regard, a notable experimental research force is still required to developing this field.

In this regard, we have conducted an investigation impact of the different parameters by using direct dye on cotton and cotton viscose blended fabrics. The effect of salt, M:L ratio is studied before. But in this research, we are comparing with each other and give a clear picture of the auxiliaries in terms of $\mathrm{K} / \mathrm{S}$ value, washing fastness and rubbing fastness.

\section{Methods}

Table 1.

\begin{tabular}{|c|c|c|c|c|c|c|}
\hline Chemicals & Sample-1 & Sample-2 & Sample-3 & Sample-4 & Sample-5 & Sample-6 \\
\hline Direct dye & $1 \%$ Shade & $1 \%$ Shade & $1 \%$ Shade & $1 \%$ Shade & $1 \%$ Shade & 1\% Shade \\
\hline $\mathrm{Na}_{2} \mathrm{CO}_{3}$ & $2 \mathrm{~g} / \mathrm{l}$ & & $2 \mathrm{~g} / \mathrm{l}$ & & $2 \mathrm{~g} / \mathrm{l}$ & \\
\hline Glaubar Salt & $10 \mathrm{~g} / \mathrm{l}$ & & $10 \mathrm{~g} / \mathrm{l}$ & & $10 \mathrm{~g} / \mathrm{l}$ & \\
\hline Wetting agent & $1 \mathrm{~g} / \mathrm{l}$ & $1 \mathrm{~g} / \mathrm{l}$ & $1 \mathrm{~g} / \mathrm{l}$ & $1 \mathrm{~g} / \mathrm{l}$ & $1 \mathrm{~g} / \mathrm{l}$ & $1 \mathrm{~g} / \mathrm{l}$ \\
\hline Sequestering agent & $1 \mathrm{~g} / \mathrm{l}$ & $1 \mathrm{~g} / \mathrm{l}$ & $1 \mathrm{~g} / \mathrm{l}$ & $1 \mathrm{~g} / \mathrm{l}$ & $1 \mathrm{~g} / \mathrm{l}$ & $1 \mathrm{~g} / \mathrm{l}$ \\
\hline Material: liquor & $1: 15$ & $1: 15$ & $1: 10$ & $1: 10$ & $1: 15$ & $1: 15$ \\
\hline Time & $60 \mathrm{~m}$ & $60 \mathrm{~m}$ & $60 \mathrm{~m}$ & $60 \mathrm{~m}$ & $60 \mathrm{~m}$ & $60 \mathrm{~m}$ \\
\hline Temperature & $100{ }^{\circ} \mathrm{C}$ & $100{ }^{\circ} \mathrm{C}$ & $100^{\circ} \mathrm{C}$ & $100{ }^{\circ} \mathrm{C}$ & $100{ }^{\circ} \mathrm{C}$ & $100^{\circ} \mathrm{C}$ \\
\hline
\end{tabular}

The whole Process have carried out in a well-structured manner. Six number of samples have prepared like sample-1 or standard recipe, without soda ash and Glauber salt, materials: liquors ratio decreased also using cotton viscose blended. Recipe have presented briefly in Table 1 .

The dyebath was prepared by adding specific amounts of dyestuffs along with the sequestering agent, wetting agent, salt, soda

\section{Experimental}

\section{Materials}

Single Jersey knit fabric specimens (160 GSM) were ready from 28 Ne carded yarn. Necessary chemicals like direct dye (DyechuRed-3R-XE), Soda Ash, Glauber Salt, wetting agent, sequestering agent, and auxiliaries were bought from Dysin-Chem Ltd (Dhaka, Bangladesh).

In addition, James H. Heal, UK had the supplier of ISO standard detergent as well as the multi-fiber fabrics to perform color fastness to wash experience, rubbing fastness tester machine. Also, spectrophotometer used to determine color strength.

All the dyestuffs, chemicals, and auxiliaries were of analytical grade and used without further purification. ash in prescribed materials-liquor. After that specimen(10 gm fabric) have immersed in a pot. The dyeing was completed by exhaust method in Sandolab infrared lab dyeing machine from Co-power Technology Ltd, Taiwan. The initial temperature was $30{ }^{\circ} \mathrm{C}$ then gradually increased up to $100{ }^{\circ} \mathrm{C}$. After treating 1 hour in $100{ }^{\circ} \mathrm{C}$ temperature, the specimen is ready for wash off. Finally performed some tests to determine the effects of different parameters [8] (Figure 1)

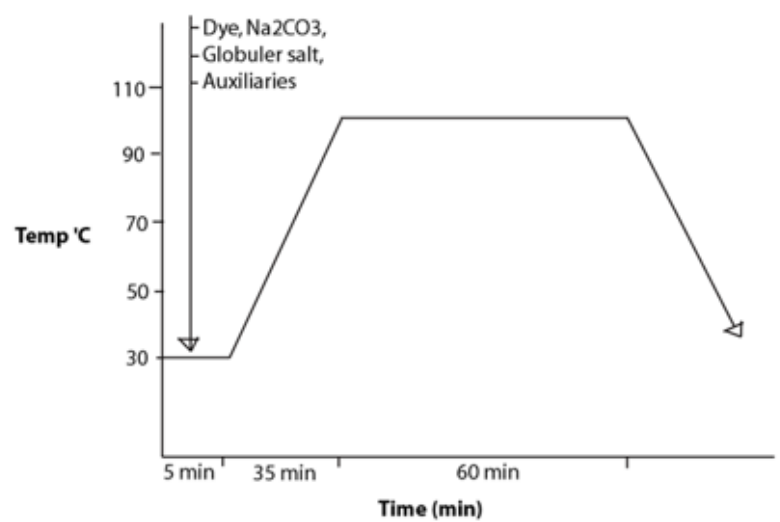

Figure 1: Dyeing curve of the knitted specimen by using direct dye. 


\section{Determination of color strength and relevant parameters}

By employing a color determination spectrophotometer (Data color 650 from China) the color yield worth of direct dyed cotton and cotton viscose blended fabric specimen was examined. The depth of color of the dyed fabric was circumscribed by investigating the K/S value of a given dyed specimen by Kubelka-Munk equation (Eq (1) [9])

$$
\frac{K}{S}=\frac{(1-R)^{2}}{2 R}
$$

Where in the equation has $\mathrm{R}$ indicates percentage of reflectance; $\mathrm{K}$ co-efficient of absorption; and S indicates scattering co-efficient of dyes. Those values came from the ratio of attenuation of the light particles because of absorption and scattering, which was found based on reflectance. Colorimetric characteristics of the specimen fabric like Lightness $\left(\mathrm{L}^{*}\right)$, redness-greenness( $\left.\mathrm{a}^{*}\right)$, yellowness-blueness $\left(b^{*}\right)$, chroma $\left(c^{*}\right)$, and hue $\left(h^{\circ}\right)$ were assessed regarding the Table 2: Color fastness to Rubbing of six no of samples.

\begin{tabular}{|c|c|c|c|}
\hline Name of group & Wet & Dry & Assessment \\
\hline Sample- 1 & $3 / 4$ & 5 & Wet and dry result in satisfactory level \\
\hline Sample- 2 & 3 & 5 & Dry rubbing fastness obtained excellent but wet retting is good \\
\hline Sample- 3 & $2 / 3$ & 4 & Dry result obtained Excellent whereas wet retting obtained good grading \\
\hline Sample- 4 & 3 & $5 / 5$ & Dry result obtained very good whereas wet retting obtained good grading \\
\hline Sample- 5 & 3 & 5 & Dry result obtained Excellent whereas wet retting obtained good grading
\end{tabular}

The ability to sustain original color of dyed fabrics when rubbing is called rubbing color fastness. Dry experiment of this is indicates the situation of fading and staining of dyed fabric when rubbed with a standard white cloth [13]. Wet rubbing color fastness means the situation of fading and retaining of dyed fabric or garments during rubbed with a standard white cloth which water content is $95 \%$ to $105 \%$.

After rolling the Crock meter 10 times with $10 \mathrm{~N}$ pressure then obtained results by using a greyscale where 1 to 5 numerical value is marked [14].
AATCC test system 173-2006 in illuminant D65, CIE $10^{\circ}$ standard observer, and large space view [10]. In order to provide an opaque look all specimen was wrapped twice and then color reflectance value was estimated 4 time on 4 different regions of the sample fabric [11].

\section{Results and Discussion}

\section{Color fastness characteristics of knitted dyed fabrics}

Color fastness is the characteristic of a dye to clutch its color during the dyed or printed textile substance is presented to diverse environmental situations [12]. The evaluation of color fastness toward washing was carried out in the typical approach in terms of the grayscale values for staining of adjacent multi-fiber fabric and change in shade. Nevertheless, rubbing fastness was assessed just color staining selection in both dry and wet conditions. The color fastness ratings of each laboratory specimens are tabularized in the Table 2 sequentially.

Direct dye shows poor color fastness but rubbing fastness shows satisfactory level due to its chemical properties. Dye rubbing fastness is good for all specimen, but wet sample is not same for all specimen.

Overall remarks to all sample of color fastness to rubbing in satisfactory level.

\section{Color fastness to wash characteristics of knitted dyed fabrics}

Table 3.

Table 3: Color fastness to wash results of all specimen.

\begin{tabular}{|c|c|}
\hline Name of group & Result \\
\hline Sample- 1 & $2 / 3$ \\
\hline Sample- 2 & $2 / 3$ \\
\hline Sample- 3 & 3 \\
\hline Sample- 4 & $3 / 4$ \\
\hline Sample- 5 & $3 / 4$ \\
\hline Sample- 6 & $3 / 4$ \\
\hline
\end{tabular}

\section{Investigation of color strength}

The color strength or depth of shade of cotton and cotton viscose knit fabric samples with changing salt, soda ash, Materials: Li- quor was investigated by K/S value which numerically represents the essence of the coloring substance cover as well as a simple technique to circumscribe a color as a concentration due to the light-absorbing and scattering [15] (Figure 3). 
M:L (less) > standard $>$ without salt \&M:L (less) $>$ without salt Standard cotton+ Viscose $<$ cotton + viscose without the salt.

Figure 2 indicates that when M:L is decreased then dye uptake is increased When M:L decreased then dye concentration in dye bath is increased as a result fibers get more opportunity to create bond with direct dye .In additions, $\operatorname{salt}\left(\mathrm{Na}_{2} \mathrm{CO}_{3}\right)$ functionate to neutralize fiber surface as a result dye attached significantly in fiber surface. As a result, absence of salt shows significantly less absorption.

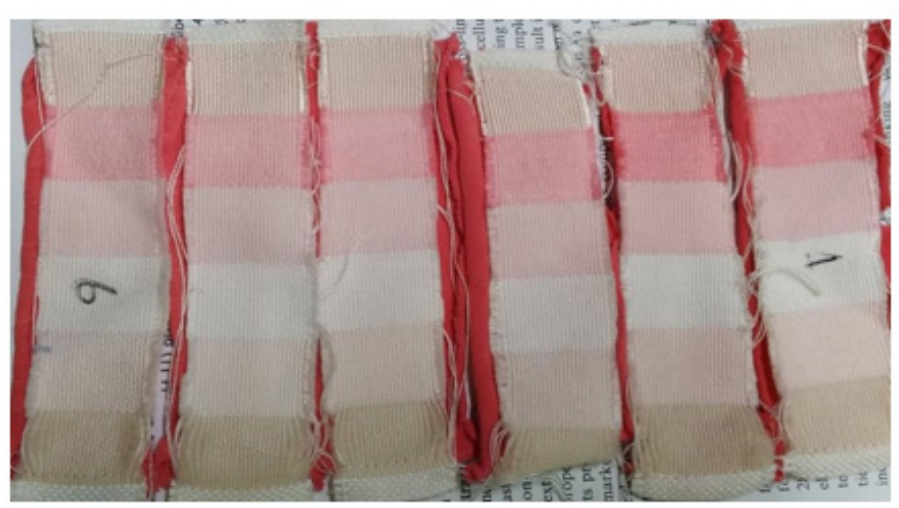

Figure 2: Specimen picture of color fastness to wash with multi-fiber.

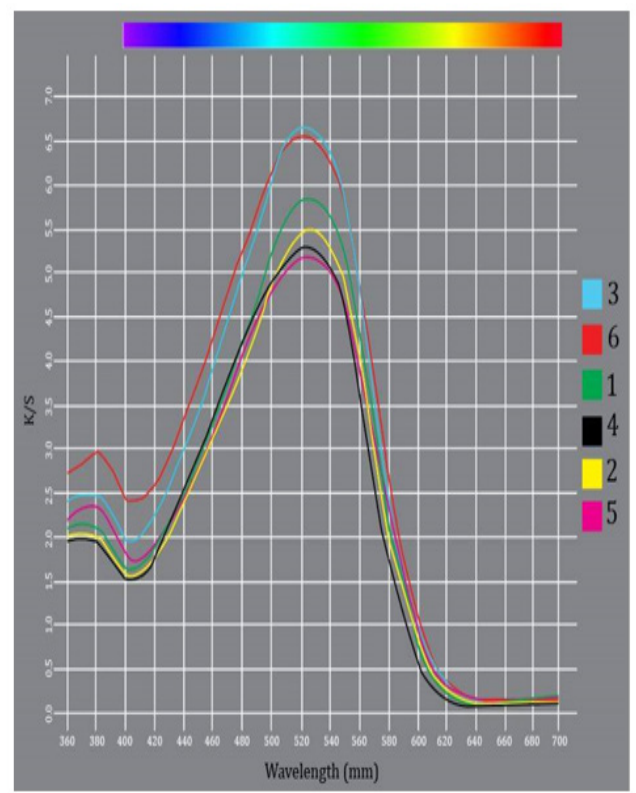

Figure 3: Color Strength or K/S value of specimen by using Data Color Technology.

Also, Cotton's degree of polymerization is 5000 and viscose's only 175 . As a result, viscose knit fabrics absorption is lower than cotton. Beside this, In the case of cotton viscose blend standard sample result obtain good color strength but parallel sample is unexpectedly high due to material preparations error. Overall, Absence of salt, soda ash decrease absorption and decrease of M:L increase absorption or dye uptakes.

\section{Conclusion}

The effect of cotton and cotton viscose blended fabrics with direct dye has been extensively investigated. The detailed experimental results have revealed that the absence of Salts and Soda Ash (Na2CO3) decrease the overall dye take-up as well as reduction of Material: Liquor progresses the dye absorption or take-up of the knitted specimen. Also, viscose cotton blended specimen exhibits inadequate dye absorption and overall weaker result comparing cotton. Color fastness to wash, color strength by spectrophotometer device and rubbing color fastness has determined to get perfect scenario of samples. This finding will apply in the dyeing industry where they get proper guidance to use dyes, salt, and auxiliaries. As a result, the dye house will be financially benefited and decrease environmental pollutions caused by the controlled use of chemicals.

\section{Acknowledgments}

The authors are thankful to the Department of Textile Engineering, Dhaka University of Engineering and Technology, Gazipur, for permitting to practice its lab facility. Specific appreciation is also extended to the Mr. Abdul Hannan, Associate professor, Department of Textile Engineering, DUET, Gazipur for guidelines in this research. 


\section{Conflict of Interest}

Authors declare no conflict of interest.

\section{References}

1. Shore J (1995) Cellulosics Dyeing. Bradford, West Yorkshire: Society of Dyers and Colorists.

2. Broadbent AD (2001) Basic Principles of Textile Coloration. Bradford: Society of Dyers and Colorists.

3. Clark M (2011) Handbook of textile and industrial dyeing. Oxford Philadelphia: Woodhead Publishing Limited, USA.

4. Burkinshaw SM, Salihu G (2019) The role of auxiliaries in the immersion dyeing of textile fibres: Part 4 theoretical model to describe the role of liquor ratio in dyeing cellulosic fibres with direct dyes in the absence and presence of inorganic electrolyte. Dyes and Pigments 161: 565-580.

5. Abedi D, Mortazavi SM, Mehrizi MK, Feiz M (2008) Antimicrobial Properties of Acrylic Fabrics Dyed with Direct Dye and a Copper Salt Textile Research Journal 78(4): 311-319.

6. Gupta D, Haile A (2007) Multifunctional properties of cotton fabric treated with chitosan and carboxymethyl chitosan. Carbohydrate Polymers 69(1): 164-171.

7. Nicola M, Alsafi Z, Sohrabi C, Kerwan A, Al-Jabir A, et al. (2020) The SocioEconomic Implications of the Coronavirus and COVID-19 Pandemic: A Review. International Journal of Surgery 78: 185-193.

8. (2013) AATCC - TM061-TM61-TM 61 Test Method for Colorfastness to Laundering: Accelerated 9.
9. Christy AA, Kvalheim OM, Velapoldi RA (1995) Quantitative analysis in diffuse reflectance spectrometry: A modified Kubelka-Munk equation. Vibrational Spectroscopy 9(1): 19-27.

10. Yang L, Kruse B (2004) Revised Kubelka-Munk theory I Theory and application. J Opt Soc Am A Opt Image Sci Vis 21(10): 1933-1941.

11. Yang L, Kruse B, Miklavcic SJ (2004) Revised Kubelka-Munk theory II Unified framework for homogeneous and inhomogeneous optical media. J Opt Soc Am A Opt Image Sci Vis 21(10): 1942-1952.

12. Cheek L (1990) Dyeing and Colorfastness Characteristics of Direct-Dyed Ramie in Comparison to Flax and Cotton. Clothing and Textiles Research Journal 8(2): 38-42.

13. Sufian MA, Hannan MA, Rana MM, Huq MZ (2016) Comparative Study of Fastness Properties and Color Absorbance Criteria of Conventional and Avitera Reactive Dyeing on Cotton Knit Fabric. European Scientific Journal 12(15): 352.

14. (2016) AATCC - TM008-TM8-TM 8 Colorfastness to Crocking: Crockmeter Method.

15. Yang L, Miklavcic SJ (2005) Revised Kubelka-Munk theory. III. A general theory of light propagation in scattering and absorptive media. J Opt Soc Am A Opt Image Sci Vis 22(9): 1866-1873. 